\title{
Psychological Distress of Young Adults in Relation to Certain Demographic Variables
}

\author{
Saheera, K. $\mathrm{T}^{1 *}$, Manikandan, $\mathrm{K}^{2}$
}

\section{ABSTRACT}

Early adulthood is a period of adjustment to new expectations and roles that make it a distinctive and a difficult period in the life span. The Objective of the study was to find out the extent of psychological distress among young adults and to know how it is related to the demographic variables. Participants for the present study consisted of 224 young adults (age=20-45 years) from various institutions as well as residence in the Malappuram and Calicut district of Kerala, India. Psychological Distress Scale and Personal information sheet was used to measure Psychological distress and demographics variables like age, sex, marital status, employment status and birth order. Results revealed that there exists significant sex difference in stress, depression, and overall psychological distress, marital status as well as birth order has no role in psychological distress and unemployed subjects experience more depression than employed participants.

Keywords: Anxiety, Depression, Demographics, Psychological distress, Sex, Stress.

A human beings daily life is bound by a number of psychological factors. Stress is a major factor in achieving a feeling of well-being and ongoing mental wellness. Stress is an everyday part of life and can be a source of energy or a source of impaired mental health. Everyone feels a sense of emotional strain, tension and anxiety at times. Different individuals can cope with differing levels of stress. Sometimes, individuals feel completely overloaded by what is going on in their lives. Because, each individual experiences life in unique ways, circumstances that one enjoys may be stressful to others. The stress can lead to depression, anxiety, frustration and other symptoms in the individual which in turn negatively affect one's psychological wellbeing.

Stress is quite different in meaning from distress on its severity. Hans Selye (1907-1982), an Austrian born Canadian endocrinologist differentiated between the unpleasant/ harmful variety of stress called distress (in Latin, dis = bad) and the beneficial and motivating stress called eustress (in Greek, Eu = good).

Events that cause distress for different individuals vary. Some find events such as finding a new job or planning a trip as sources of distress. Others find troubles at home or on job as distressing.

\footnotetext{
${ }^{1}$ Research Scholar, Department of Psychology, University of Calicut, Kerala, India.

${ }^{2}$ Associate Professor, Department of Psychology, University of Calicut, Kerala, India. *Corresponding Author

(C) 2015 I T Saheera, K Manikandam; licensee IJIP. This is an Open Access Research distributed under the terms of the Creative Commons Attribution License (http://creativecommons.org/licenses/by/2.0), which permits unrestricted use, distribution, and reproduction in any Medium, provided the original work is properly cited.
} 


\section{Psychological Distress of Young Adults in Relation to Certain Demographic Variables}

Major life changes such as marriage, divorce, accident or death of loved one may also cause distress. Distress also increases when one feels a lack of support from those around them.

Early adulthood extends from the age 20 to approximately forty five, when the physical and psychological changes which accompany the beginning of the loss of reproductive capacity appear. It is a period of adjustment to new expectations and roles such as that of spouse, parent and breadwinner and to develop new attitudes, interests and values in keeping with these new roles. These adjustments make early adulthood a distinctive period in the life span and also a difficult one.

Recently, there are many studies regarding the relationship between psychological distress and psychosocial variables. Personality has a role in the psychological distress. Maladaptive personality traits were found to be associated with maladaptive coping and greater psychological distress (Irelanda, Browna, \& Ballarinia, 2006). The distressed (Type D) personality (the combination of negative affectivity and social inhibition traits) is found to be associated with psychological distress (Svansdottira, Broekb, Karlssond, Thorgilssonf, \& Denolletb, 2013).

Certain demographic variables may influence the psychological distress of young adults. Among these, types of employment and employment status have a greater role. The relations between lengths of unemployment and psychological distress are positively related among young adults (Winefield \& Tiggemann, 1990). High psychological distress level was associated with increased odds of physical inactivity among both men and women (Muhsena, Sandalona, Grossb, \& Greena, 2010; Khana, Brownb, \& Burtonb, 2013). Compared to those sitting at work less than 3 h/day, men sitting more than $6 \mathrm{~h}$ /day had increased prevalence of moderate psychological distress and women sitting more than $6 \mathrm{~h} /$ day had an increased prevalence of moderate and high distress.

Markwicka, Ansaria, Sullivan, and McNeilc (2015) explored the association between psychological distress, socioeconomic status (SES) and socio-demographic characteristics and found that psychological distress has significant correlation with negative perceptions of the residential neighborhood, lack of social support from family, social and civic distrust, and sociodemographic variables (age, sex, marital status, household composition, and locality) and the recurrent history of psychological distress was associated with a progressively increasing risk of future distress in adults (Jokela et al., 2011). Psychological distress is also related to the geographical area of living. In a country wise comparison, people living in a smaller urban settlement or village was associated with significantly higher odds for psychological distress compared to people living in the country capital. Lower social support was a strong correlate of psychological distress in all locations except capital cities (Stickleya, Koyanagid, Robertsa, \& McKeea, 2015). 


\section{Psychological Distress of Young Adults in Relation to Certain Demographic Variables}

There are studies which mention the consequences of psychological distress on health also. One of the recent studies by Martiniuk (2010) aimed to assess the relationship between psychological distress and risk of motor vehicle crashes. Results revealed that compared to the referent group with low or no distress, a protective effect against crash was observed for young people who reported a moderate amount of psychological distress. Suicide is a leading cause of death among young adults and depression and anxiety may be responsible for the increased suicide rates (Caprona, Lamisb, \& Schmidta, 2014).

There are variances in psychological distress among various age groups (Goulia, 2012) and it was found to increase in young people over time ( Sweeting, West, Young \& Der, 2010). Kaplan and Marks (1990) found that as acculturation increased, distress significantly increased in young adults but tended to decrease in older adults.

Marriage and related factors play a great role in psychological distress. Psychological distress was greater among lone mothers than married mothers (Hopea, Powera, Rodgersb, 1999). Those whose parents had divorced reported more distress in midlife, particularly if they too had experienced marital breakdown (Kuha, Hardya, Rodgersb, \& Wadswortha, 2002). The presence of children is a particularly significant source of increased psychological distress in union dissolutions (Tavaresa, Patricio, \& Aassvea, 2013).

Other factors related to psychological distress are sleep quality (Hilla, Burdetteb, \& Halec, 2009) and neighborhood problems (e.g., vandalism and disturbance, street litter, air and noise pollution) (Steptoe \& Feldman, 2001).

Individuals are living in a fast moving society where everybody strives to excel their life. It is mandatory for one to be healthy both physically as well as psychologically to attain these excellence. Unfortunately, the unhealthy ways of competition make many problems to the individual as well as to society. Psychological distress is one among these problems.

Psychological distress is a concept which is defined differently by different people in different reviews. Here the investigators viewed psychological distress as condition in which the individuals are experiencing anxiety in general, depression and stress. It is a state where the individual lack mental health and in turn leads to psychological problems. It is a serious issue of people in all most all culture. Due to drastic changes and demands from the environment, the individuals are incapable to cope with these psychological states.

Young adulthood is a developmental period between adolescence and older adulthood, whose age ranges from 20-45 years. This is an important period where the individual faces drastic behavioral changes in their role. A study focuses on the assessment of psychological distress among three subgroups of Vietnamese Youth: adolescents, unaccompanied minors, and young adults and the result indicate relatively high levels of depression and anxiety for the young adult 


\section{Psychological Distress of Young Adults in Relation to Certain Demographic Variables}

group, although anxiety appeared high across all three groups (Felsman, Leong, Johnson, \& Felsman, 1990).

From these point of view, the investigators decided to know the extent of psychological distress among young adults in the locality and how it is related to the demographic variables such as age, sex, marital status, employment status and birth order.

\section{OBJECTIVES}

- To find out the extent of psychological distress among young adults

- To know how Psychological distress is associated with certain demographic variables.

\section{METHOD}

\section{Participants}

Participants of this study consisted of 224 students and young adults residing in Malappuram and Calicut districts of Kerala, India. The age of the participants ranges from 20 to 45 years. Out of these 224 participants, 95 (42.4\%) were male and 129 (57.6\%) were female. Regarding the marital status, 155 (69.2\%) were married and 69 (30.8\%) were unmarried. Among the total participants 95 (42.4\%) are employed and 129 (57.6\%) are unemployed and 68 (30.4\%) were first born, 63 (28.1\%) second born and 93 (41.5\%) were last born.

\section{Instruments}

1. Psychological Distress Scale: Psychological Distress Scale was developed by Saheera and Manikandan (2015) to measure Depression, Anxiety and Stress of the young adults. Psychological distress scale consists of 18 items: of these, 4 items belongs to stress, 7 belongs to anxiety and 7 on depression. Reliability of the Psychological distress was estimated through Cronbach Alpha and it was found to be .87 for the whole scale. Authors also reported face validity for Psychological Distress Scale.

2. Personal data sheet: Personal data sheet was used to collect socio-demographic variables like age, sex, marital status, employment status, birth order and number of family members etc.

\section{Procedure}

The investigators directly met the subjects in their residents and explained the purpose, objectives and relevance of the study and solicited their whole hearted cooperation for the study. After receiving written consent from each participant the psychological Distress Scale and Personal Data Sheet were handed over to them and requested to complete as per the direction printed on the instruments itself. Even then the investigator gave oral instructions to the participants so that the responses would be better. After completion of both instruments, it was collected back and checked for omission. Then both instruments were scored/coded as per the scoring key and entered into a spread sheet for further statistical analysis. 


\section{Psychological Distress of Young Adults in Relation to Certain Demographic Variables}

\section{RESULTS AND DISCUSSION}

Research using quantitative methodologies has tended to focus on the psychological distress among various populations and there is a growing body of research demonstrating strong relationship between adulthood and psychological distress. Many of these researches focus on the influence of demographic variables on the psychological distress of adult population. Here, the investigators had studied the demographic variables such as age, sex, employment status, marital status and birth order and its influence on the psychological distress of young adults.

To find out whether there exists any significant correlation between the components of psychological distress, product moment correlation was calculated and the results are presented in table 1.

Table 1Correlation of Psychological distress and its components

\begin{tabular}{|l|l|l|l|l|}
\hline \multicolumn{1}{|c|}{ Variables } & \multicolumn{1}{c|}{ Stress } & \multicolumn{1}{c|}{ Anxiety } & \multicolumn{1}{c|}{ Depression } & Psychological Distress \\
\hline Stress & - & & & \\
\hline Anxiety & $.363^{* *}$ & - & & \\
\hline Depression & $.405^{* *}$ & $.542^{* *}$ & - & \\
\hline Psychological Distress & $.645^{* *}$ & $.833^{* *}$ & $.868^{* *}$ & - \\
\hline
\end{tabular}
$* * \mathrm{p}<.01$

From the Table 1, it can be seen that there is a significant positive correlation among psychological distress and its components. The results indicate that the three constructs- Stress, Anxiety and Depression can explain the mental health of an individual.

\section{Psychological distress and sex}

To know whether there exists any sex difference on psychological distress, mean scores of males and females were compared using ' $t$ ' test and the results are presented in table 2.

Table 2 Mean, SD, and 't' value of Stress, Anxiety, Depression and Psychological Distress by Sex

\begin{tabular}{|c|c|c|c|c|c|}
\hline Variables & Sex & $\mathbf{N}$ & Mean & SD & 't' value \\
\hline \multirow{2}{*}{ Stress } & Male & 95 & 4.53 & 2.736 & \multirow{2}{*}{$3.51 * *$} \\
\hline & Female & 129 & 5.95 & 3.366 & \\
\hline \multirow{2}{*}{ Anxiety } & Male & 95 & 5.91 & 5.429 & \multirow{2}{*}{0.73} \\
\hline & Female & 129 & 6.43 & 5.313 & \\
\hline \multirow{2}{*}{ Depression } & Male & 95 & 5.29 & 5.709 & \multirow{2}{*}{$2.02 *$} \\
\hline & Female & 129 & 6.90 & 6.081 & \\
\hline \multirow{2}{*}{ Psychological Distress } & Male & 95 & 15.73 & 11.453 & \multirow{2}{*}{$2.27 *$} \\
\hline & Female & 129 & 19.28 & 11.693 & \\
\hline
\end{tabular}
${ }^{*} \mathrm{p}<.05,{ }^{* *} \mathrm{p}<.01$

From table 2, it can be seen that there exists significant difference between males and females on their reported experience of stress $(\mathrm{t}=3.51, \mathrm{p}<.01)$, depression $(\mathrm{t}=2.02, \mathrm{p}<.05)$ and over all 


\section{Psychological Distress of Young Adults in Relation to Certain Demographic Variables}

psychological distress $(\mathrm{t}=2.27, \mathrm{p}<.05)$. Females were experiencing more stress (Mean=5.95), Anxiety (Mean=6.43), Depression (Mean=6.90) and psychological distress (Mean=19.28) than males. This result indicates that sex has a significant role in developing stress, depression and psychological distress among young adults. Stress was found to be higher in females than males, which implies the role of women in Indian context. In India, women has to take responsibilities from multiple aspects like home, office, child rearing, and caring for own and in-law parents. Men are found to be the breadwinners only. If any crisis emerges within the family, a woman has to take the responsibility of that and she has to manage the office work also. Cleary and Mechanic (1983) reported that women experience distress than men. They also reported that employed married women experience less distress than house wife's. If stress increase naturally anxiety may also increase since these variables were positively correlated. If stress and anxiety are high then the individuals will have depression.

\section{Psychological Distress and Marital status}

In a society getting married and having a family is important and will change their lives. Both individuals have to modify their personal behavior pattern for the smooth functioning of the family. This may result in various modifications in their day to day life like work etc. Here the investigators attempted to know whether marital status has any significant effect on stress, anxiety, depression and psychological distress, mean scores of these variables were compared using ' $\mathrm{t}$ ' test and the results presented in table 3.

Table 3, Mean, SD, and 't' value of Stress, Anxiety, Depression and Psychological Distress on Marital Status

\begin{tabular}{|c|c|c|c|c|c|}
\hline Variables & Marital Status & $\mathbf{N}$ & Mean & SD & 't' Value \\
\hline \multirow{2}{*}{ Stress } & Married & 155 & 5.37 & 3.283 & \multirow{2}{*}{0.17} \\
\hline & Unmarried & 69 & 5.29 & 2.981 & \\
\hline \multirow{2}{*}{ Anxiety } & Married & 155 & 6.39 & 5.477 & \multirow{2}{*}{0.77} \\
\hline & Unmarried & 69 & 5.80 & 5.092 & \\
\hline \multirow{2}{*}{ Depression } & Married & 155 & 5.91 & 5.694 & \multirow{2}{*}{1.16} \\
\hline & Unmarried & 69 & 6.91 & 6.528 & \\
\hline \multirow{2}{*}{$\begin{array}{l}\text { Psychological } \\
\text { Distress }\end{array}$} & Married & 155 & 17.67 & 11.590 & \multirow{2}{*}{0.19} \\
\hline & Unmarried & 69 & 18.00 & 12.023 & \\
\hline
\end{tabular}

From table 3, it can be seen that marital status of the participants has nothing to do with their marital status. This result narrates the strength and importance of family system prevailing in Indian society. Here, every individual belongs to a family and develop by utilizing resources from and for family. Marriage is a custom in India and definitely plays a big role in one's life. 


\section{Psychological Distress of Young Adults in Relation to Certain Demographic Variables}

\section{Psychological Distress and Employment status}

Another aspect of human being is working for earning or satisfying their personal needs through performing some activity which express their talents or skills. Work is an essential thing in a human life. How employment of a person influence their mental health, the investigators compared mean scores of employed and unemployed on stress, anxiety, depression and psychological distress by computing ' $t$ ' value of each variable. The results of ' $t$ ' test is presented in table 4.

Table 4, Mean, SD, and 't' value of Stress, Anxiety, Depression and Psychological Distress by Employment Status

\begin{tabular}{|c|c|c|c|c|c|}
\hline Variables & $\begin{array}{l}\text { Employment } \\
\text { Status }\end{array}$ & $\mathbf{N}$ & Mean & SD & ' $t$ ' value \\
\hline \multirow{2}{*}{ Stress } & Employed & 95 & 5.04 & 2.968 & \multirow{2}{*}{1.22} \\
\hline & Unemployed & 129 & 5.57 & 3.333 & \\
\hline \multirow{2}{*}{ Anxiety } & Employed & 95 & 6.80 & 5.554 & \multirow{2}{*}{1.42} \\
\hline & Unemployed & 129 & 5.78 & 5.186 & \\
\hline \multirow{2}{*}{ Depression } & Employed & 95 & 5.26 & 5.601 & \multirow{2}{*}{$2.07 *$} \\
\hline & Unemployed & 129 & 6.92 & 6.149 & \\
\hline \multirow{2}{*}{$\begin{array}{l}\text { Psychological } \\
\text { Distress }\end{array}$} & Employed & 95 & 17.11 & 11.471 & \multirow{2}{*}{0.73} \\
\hline & Unemployed & 129 & 18.26 & 11.885 & \\
\hline
\end{tabular}

${ }^{*} \mathrm{p}<.05$

From table 4, it can be seen that only on depression there exist a significant mean difference $(\mathrm{t}=2.07, \mathrm{p}<.05)$ between employed and unemployed individual. Unemployed youths scored higher mean score on depression compared to employed youths. In all other variables the groups did not differ significantly. Unemployed young adults experience more depression than employed young adults. Young adulthood is a critical period in the life as it demanding a major shift in role from a resource taker to a resource giver. To have success in this regard, it is very essential for each individual to be financially stable. Persons who are unemployed might have the feeling that their education and caliber are in futile and this may lead to depression.

\section{Psychological distress and Birth order}

The ordinal position of a person in a family is another important variable which is related to many personal as well as social variables. In this study the birth order of the individuals were collected and classified into three groups as first born, second born and later born. To know whether birth order of a person has any significant effect on stress, anxiety, depression and psychological distress one-way ANOVA was carried out and the results are presented in table 5. 
Psychological Distress of Young Adults in Relation to Certain Demographic Variables

Table 5, One-way ANOVA of Psychological distress and its components by Birth order

\begin{tabular}{|c|c|c|c|c|c|}
\hline Variables & Source Variance & Sum of Squares & Df & $\begin{array}{l}\text { Mean } \\
\text { Square }\end{array}$ & $\mathbf{F}$ \\
\hline \multirow{3}{*}{ Stress } & Between Groups & .090 & 2 & 0.045 & \multirow{3}{*}{0.004} \\
\hline & Within Groups & 2264.441 & 221 & 10.246 & \\
\hline & Total & 2264.531 & 223 & & \\
\hline \multirow{3}{*}{ Anxiety } & Between Groups & 39.734 & 2 & 19.867 & \multirow{3}{*}{0.690} \\
\hline & Within Groups & 6359.405 & 221 & 28.776 & \\
\hline & Total & 6399.138 & 223 & & \\
\hline \multirow{3}{*}{ Depression } & Between Groups & 33.217 & 2 & 16.608 & \multirow{3}{*}{0.464} \\
\hline & Within Groups & 7905.064 & 221 & 35.770 & \\
\hline & Total & 7938.281 & 223 & & \\
\hline \multirow{3}{*}{$\begin{array}{l}\text { Psychological } \\
\text { Distress }\end{array}$} & Between Groups & 144.425 & 2 & 72.212 & \multirow{3}{*}{0.525} \\
\hline & Within Groups & 30376.964 & 221 & 137.452 & \\
\hline & l & 30521.388 & 223 & & \\
\hline
\end{tabular}

Analysis of Variance of psychological distress by birth order revealed that birth order or the ordinal position of an individual doesn't have any significant effect on stress, anxiety, depression and psychological distress. Theoretically there will be significant relation between birth order and anxiety. But in this model birth order showed no significant effect on anxiety of the participants.

To have a clear understanding, the mean scores of stress, anxiety, depression and psychological distress of first born, second born and later born were calculated and presented in table 6 .

Table 6, Mean, SD, and N of Psychological Distress and its components by Birth Order

\begin{tabular}{|l|l|l|l|l|l|}
\hline Birth Order & Statistics & Stress & Anxiety & Depression & $\begin{array}{l}\text { Psychological } \\
\text { distress }\end{array}$ \\
\hline $\begin{array}{l}\text { First Born } \\
(\mathrm{N}=68)\end{array}$ & Mean & 5.34 & 6.60 & 6.72 & 18.66 \\
\cline { 2 - 6 } & SD & 3.079 & 5.636 & 6.664 & 12.282 \\
\hline $\begin{array}{l}\text { Second Born } \\
(\mathrm{N}=63)\end{array}$ & Mean & 5.32 & 5.56 & 5.71 & 16.59 \\
\cline { 2 - 6 } & SD & 3.636 & 4.983 & 5.440 & 11.038 \\
\hline $\begin{array}{l}\text { Later Born } \\
(\mathrm{N}=93)\end{array}$ & Mean & 5.37 & 6.37 & 6.19 & 17.92 \\
\hline \multirow{2}{*}{$\begin{array}{l}\text { Total } \\
(\mathrm{N}=224)\end{array}$} & SD & 2.966 & 5.409 & 5.800 & 11.757 \\
\hline
\end{tabular}

From table 6, it can be seen that the mean stress scores of first, second and later born was more or similar. But in the case of anxiety, first born scored higher mean scores compared to second and later born. Similarly, mean depression score was found to be higher among first born. 


\section{Psychological Distress of Young Adults in Relation to Certain Demographic Variables}

Psychological distress the sum total of stress, anxiety and depression was also found to be higher among first born. All these mean scores of psychological distress and its components except stress indicates that first born individuals were experiencing more anxiety, depression and psychological distress than second or later born. It implies that the first born are more prone to anxiety and depression.

\section{CONCLUSION}

The objective of the study was to find out the influence of certain demographic variables on psychological distress of young adults. Psychological distress is a serious issue and mental health professionals were heavily interested in. The fast moving nature of our systems makes its members under great distress. And we can see some differences in the degree of this distress among certain group. Young adulthood is a period where people are facing psychological distress to a greater extent. There are many reasons for this. The results of the present study revealed that demographic variables like sex, employment status and birth order has been significantly playing certain role on their psychological distress.

Females experience more stress, depression and psychological distress than males. The demands of our cultural systems make our women under great distress. They have to manage home as well as office works. Even though sharing of the house hold tasks reduces the burden of women, men are more oriented towards decision makers and breadwinners. And it is a common saying that women are emotional being, giving much importance to the emotional aspect than males. Even a simple and solvable issue in the family or work produces great disturbance for women which also contributes to the increasing nature of stress, depression and psychological distress.

Unemployment in young adulthood is a contributing factor in depression. As we know that, young adulthood demands many changes in the roles and each individual needs to be financially independent. Persons who are unemployed might have the feeling that their education and caliber are in futile and feel good for nothing fellows. This may also question their mental health. Good job in our culture is a sign of status for young adulthood as it is the period of developing new commitments such as marriage and parenthood.

Another influential demographic variable, - ordinal position - showed no significant difference on participants' psychological distress. First and later born were experiencing more anxiety and depression than the second born. Generally, the first born within a family is the centre of attraction in all respect. The treatment he/she gets from the family is quite different from the rest. The last born are one who is getting more pampering from the whole elderly. This makes the two groups unique in character. This all may be the reason for higher anxiety and depression among these groups. 


\section{Psychological Distress of Young Adults in Relation to Certain Demographic Variables}

While analyzing the overall results, it can be seen that the first born female experience more psychological distress than the other counterparts. It may be because of the particular feminine nature we have discussed earlier. Hence, focusing well designed research in reducing the psychological distress of the mentioned group will have the greatest impact on the wellbeing of young adults and the society as a whole.

\section{REFERENCES}

Caprona, D. W., Lamisb, D. A., \& Schmidta, N. B. (2014). Test of the depression distress amplification model in young adults with elevated risk of current suicidality. Psychiatry Research, 219, 531-535.

Cleary, P. D., \& Mechanic, D. (1983). Sex difference in Psychological Distress among married People, Journal of Health and Social Behavior, 24(2), 111-121.

Felsman, J. K., Leong, F. T., Johnson, M. C., \& Felsman, I. C. (1990). Estimates of psychological distress among Vietnamese refugees: Adolescents, unaccompanied minors and young adults. Social Science \& Medicine, 31, 1251-1256.

Goulia, P., Papadimitriou, I., Machado, M. O., Mantas, C. S., \& Pappa, C. (2012). Does psychological distress vary between younger and older adults in health and disease? Journal of Psychosomatic Research, 72, 120-128.

Hilla, T. D., Burdetteb, A. M., \& Halec, L. (2009). Neighborhood disorder, sleep quality, and psychological distress: Testing a model of structural amplification. Health \& Place, 15, 1006-1013.

Hopea, S., Powera, C., \& Rodgersb, B. (1999). Does financial hardship account for elevated psychological distress in lone mothers? Social Science \& Medicine, 49, 1637-1649.

Hurlock, H. B. (1980). Developmental Psychology, A lifespan Approach, $\left(5^{\text {th }}\right.$ Ed), New Delhi: Tata Mc-Graw Hill Company Pvt, Ltd.

Irelanda, J. L., Browna, S. L., \& Ballarinia, S. (2006). Maladaptive personality traits, coping styles and psychological distress: A study of adult male prisoners. Personality and Individual Differences, 41, 561-573.

Jokelaa, M., Manouxa, A. S., Shipleya, M. J., Ferriea, J. E., Gimenoa, D., Akbaralya, T. N., ..., Kivimakia, M. (2011). Natural course of recurrent psychological distress in adulthood. Journal of Affective Disorders, 130, 454-461.

Kahn, A. P., \& Fawsett, J. (2004). The Encyclopedia of Psychic Disorders, Vol 3, Bangalore: Viva books Pvt Ltd.

Kaplan, M. S., \& Marks, G. (1990). Adverse effects of acculturation: Psychological distress among Mexican American young adults. Social Science \& Medicine, 31, 1313-1319.

Khana, A., Brownb, W. J., \& Burtonb, N. W. (2013). What physical activity contexts do adults with psychological distress prefer? Journal of Science and Medicine in Sport, 16, 417421.

Kuha, D., Hardya, R., Rodgersb, B., \& Wadswortha, M. E. J. (2002). Lifetime risk factors for women's psychological distress in midlife. social Science \& Medicine,55,1957-1973. 


\section{Psychological Distress of Young Adults in Relation to Certain Demographic Variables}

Marini, M. M. (1978). The transition to adulthood: sex differences in educational attainment and age at marriage. American sociological review, 43, 483-507.

Markwicka, A., Ansaria, Z., Sullivan, M., \& McNeilc, J. (2015). Social determinants and psychological distress among Aboriginal and Torres Strait islander adults in the Australian state of Victoria: A cross-sectional population based study, Social Science \& Medicine, 128,178-187.

Martiniuk, A., Ivers, R. Q., Glozier, N., Patton, G. C., Senserrick, T., Boufous, S., ..., Norton, R. (2010). Does Psychological Distress Increase the Risk for Motor Vehicle Crashes in Young People? Findings From the DRIVE Study. Journal of Adolescent Health. 47, 488495.

Muhsena, K., Sandalona, N. G., Grossb, R., \& Greena, M. S. (2010). Psychological distress is independently associated with physical inactivity in Israeli adults. Preventive Medicine, 50, 118-122.

Phongsavana, P., Cheyb, T., Baumana, A., Robert Brooks, R., \& Siloveb, D. (2006). Social capital, Socio-economic status and Psychological distress among Australian adults. Social Science \& Medicine, 63, 2546-2561.

Saheera, K. T., \& Manikandan, K. (2015). Psychological Distress Scale, Department of Psychology, University of Calicut, Kerala.

Stickleya, A., Koyanagid, A., Robertsa, B., \& McKeea, M. (2015). Urban-rural differences in psychological distress in nine countries of the former Soviet Union. Journal of Affective Disorders, 178, 142-148.

Svansdottira, E. B., Broekb, K. C., Karlssond,H. D., Thorgilssonf, D. T., \& Denolletb, J. (2013). The distressed (Type D) and Five-Factor Models of personality in young, healthy adults and their association with emotional inhibition and distress. Personality and Individual Differences, 55, 123-128.

Sweeting, H., West, P., Young, R., \& Der, G. (2010). Can we explain increases in young people’s psychological distress over time? Social Science \& Medicine, 71, 1819-1830.

Tavaresa, L. P., \& Aassvea, A. (2013). Psychological distress of marital and cohabitation breakups. Social Science Research, 42, 1599-1611.

Winefield, A. H., \& Tiggemann, M. (1990). Length of unemployment and psychological distress: Longitudinal and cross-sectional data. Social Science \& Medicine, 31, 461-465. 